\title{
THE DISTRIBUTION OF IRON INJECTED INTRAPERITONEALLY. EVIDENCE OF SEROSAL “ABSORPTION” BY THE SMALL INTESTINE
}

\author{
By PHAIROJANA THIRAYOTHIN * AND WILLIAM H. CROSBY \\ (From the Department of Hematology, Walter Reed Army Institute of Research, \\ Washington, D. C.)
}

(Submitted for publication December 13, 1961 ; accepted February 1, 1962)

Depot iron is normally held in the body as a combination with ferritin, the iron-storage protein. A study of normal rats was undertaken concerning the deposition of iron in ferritin after the animals were given a large intraperitoneal dose of iron. A peculiarity of behavior of ferritin in the small intestine after such injection led to the observation that the intestine is able to incorporate ferritin iron through its serosal surface.

\section{MATERIALS AND METHODS}

Granick's procedure for isolation of ferritin (1) was modified to permit the use of $500 \mathrm{mg}$ of tissue, or less, as starting material. In these experiments $500 \mathrm{mg}$ of tissue was homogenized with $0.5 \mathrm{ml}$ of normal saline in a Teflon tissue grinder. The suspension was allowed to stand at room temperature for 30 minutes, then was incubated at $75^{\circ} \mathrm{C}$ for 5 minutes, and centrifuged. The supernatant layer was transferred to a tube $6 \times 50 \mathrm{~mm}$ and mixed with an equal volume of a saturated solution of ammonium sulfate. After 30 minutes at room temperature, the tube was centrifuged and the supernatant layer was discarded. The precipitate was washed with $0.05 \mathrm{ml}$ of 4 per cent $\mathrm{CdSO}_{4}$, centrifuged, and the supernatant was again discarded. Then the precipitate was dissolved in $0.05 \mathrm{ml}$ of distilled water. The yellowish-brown supernatant was picked up in a capillary tube (approximately $1.5 \times 75 \mathrm{~mm}$ ), half filling the tube; the other half was filled with a 20 per cent solution of $\mathrm{CdSO}_{4}$. One end of the tube was sealed with plasticin, and a small drop of mineral oil was placed in the other end to prevent drying. The two solutions were mixed by slowly tipping the tube end over end 5 or 6 times. The tube was labeled and then allowed to lie in a horizontal position for 48 hours. Where ferritin was extractable it could then be seen as brown crystals with low magnification (Figure 1). On the basis of concentration of crystals, the tubes were rated from 0 to 4 plus: 1 plus indicates 1 to 2 crystals of ferritin found under low power $(\times 50)$ magnification, 2 plus is 3 to 5 crystals, 3 plus is 5 to 10 crystals, and 4 plus is more than 10 .

* Royal Thai Army. Fellow in Hematology.
Albino rats of the WRCF strain, ${ }^{1}$ weighing 200 to 250 $g$, were used for the experiments. They were fed ad libitum a balanced diet (Walter Reed Rat and Mouse Diet). The rats were studied in groups of 10 or less. Group 1 was the control. Groups 2 and 3 received an intraperitoneal injection of $50 \mathrm{mg}$ of iron as a dextraniron complex (Imferon) and were killed at day 3 and day 10 , respectively. Groups 4 and 5 were given $150 \mathrm{mg}$ of iron intraperitoneally in three daily doses of $50 \mathrm{mg}$ and were killed at day 3 and day 10 , respectively, after the last injection. Animals of groups 6 and 7 were operated on prior to injection of the iron. A $3 \mathrm{~cm}$ loop of small intestine at the duodenojejunal junction was brought out of the peritoneal cavity and tacked under the skin. Two weeks elapsed before the injection to permit healing of the wound and isolation of the serosal surface of the herniated loops. There was no evidence of obstruction or circulatory impairment in the loops. The animals of group 6 were injected intraperitoneally with $50 \mathrm{mg}$ of iron and were killed 3 days after the injection. Animals of group 7 were given $25 \mathrm{mg}$ of iron by mouth and were killed 3 days later. Animals in group 8 were injected intravenously with $25 \mathrm{mg}$ of iron through the tail vein and were killed 3 days later.

The animals were killed by a blow on the head and specimens of tissue weighing $500 \mathrm{mg}$ were taken for ferritin analysis from the liver, spleen, heart, lung, kidney, stomach, duodenum, jejunum, ileum, colon, omentum, and skeletal muscle. Complete sampling was not made in every group. The duodenal sample was from the $5 \mathrm{~cm}$ length of gut distal to the pylorus; the ileum was the 5 $\mathrm{cm}$ length proximal to the cecum; the jejunal sample was taken from the middle of the upper half of the small intestine.

In some animals similar to those of group 2, smears of peritoneal exudate and sections of small intestine were fixed and stained for iron with the Prussian blue reaction. Washed cells of the exudate were treated to extract ferritin.

\section{RESULTS}

The untreated rats of group 1 were found to have no crystallizable ferritin, except in the liver

\footnotetext{
1 The Walter Reed Carworth Farm strain is derived from the Wistar strain and, as supplied, is pathogenfree.
} 

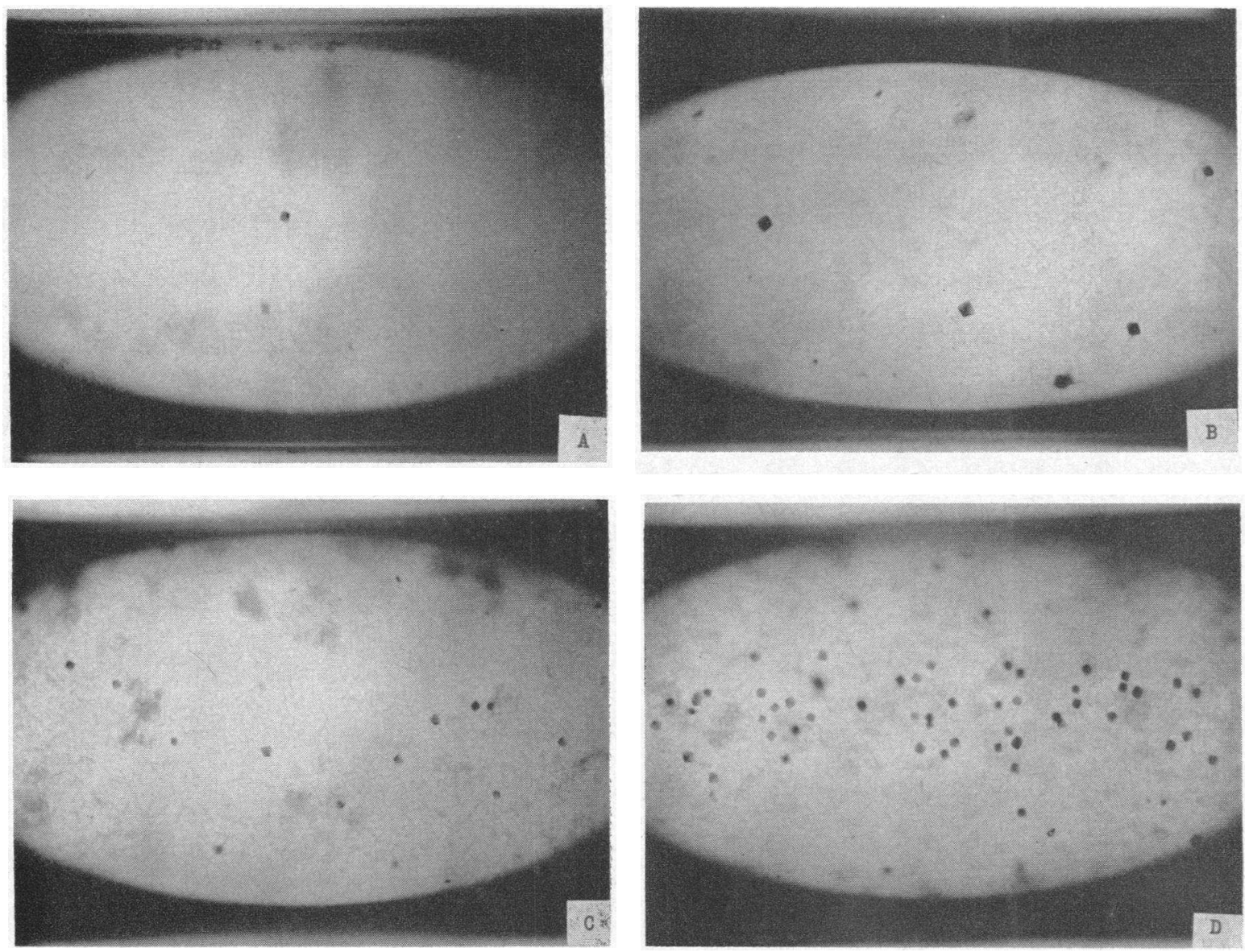

Fig. 1. Photomicrograph $(\times 50)$ to illustrate the scoring of the ferritin CRystals in the capillary tubes USED For their preparation. $\mathrm{A}=1+; \mathrm{B}=2+; \mathrm{C}=3+; \mathrm{D}=4+$.

where the results were 1 plus in seven of ten animals and 0 in three. Three days after intraperitoneal injection of $50 \mathrm{mg}$ of iron (Table I, group 2 ), the amount of ferritin recovered from liver was increased to 3 to 4 plus and 2 to 3 plus in the spleen. In addition, ferritin was 1 to 2 plus in the duodenum, 1 plus in the jejunum, and four of ten animals had 1 plus in the ileum. Ten days after the injection (Table I, group 3 ) there was still ferritin in liver and spleen, but none could be recovered from the small intestine. When the larger dose of iron $(150 \mathrm{mg}$ ) was given, the pattern of distribution of ferritin was similar after 3 days, except that the deposits were generally heavier (Table II, group 4). After 10 days no ferritin could be recovered from the small intestine; however, it had appeared in concentrations of 2 to 3 plus in the kidneys and lungs (Table II, group 5).

Three days after intraperitoneal injection into rats with an extraperitoneal loop of small intestine, ferritin was found in the small intestine adjacent to the loop, but it was not found in the loop itself (Table III, group 6). When the iron was given by mouth to these animals, ferritin was found in the herniated loop (Table III, group 7).

Three days after iron was injected intravenously it was not found in the small intestine, except for a 2 plus recovery from the ileum in two rats in which some of the iron was extravasated during injection into the tail vein.

Mononuclear cells of the peritoneal exudate were found to contain large quantities of iron which reacted to form Prussian blue. Ferritin crystals were obtained from washed cells of this exudate. In the sections of the small intestine, iron-laden phagocytes adhered to the serosa. Similar cells could be distinguished within the intestinal tissues. Iron was scattered in the muscularis; 
TABLE I

Distribution of ferritin in various tissues after intraperitoneal injection of $50 \mathrm{mg}$ of iron as iron-dextran *

\begin{tabular}{|c|c|c|c|c|c|c|c|c|c|c|c|}
\hline $\begin{array}{l}\text { Rat } \\
\text { no. }\end{array}$ & Heart & Lung & Liver & Spleen & Kidney & Stomach & $\begin{array}{c}\text { Duo- } \\
\text { denum }\end{array}$ & $\begin{array}{l}\text { Jeju- } \\
\text { num }\end{array}$ & Ileum & Colon & $\begin{array}{l}\text { Skeletala } \\
\text { muscle }\end{array}$ \\
\hline \multicolumn{12}{|c|}{ Group 2} \\
\hline 1 & - & - & ++++ & +++ & - & - & ++ & + & + & - & - \\
\hline 2 & - & - & & ++ & - & $=$ & + & + & - & - & - \\
\hline 3 & - & - & & ++ & - & - & + & + & - & - & - \\
\hline 4 & - & - & & ++ & - & - & + & + & - & - & - \\
\hline $\begin{array}{l}5 \\
6\end{array}$ & $\bar{z}$ & $\bar{z}$ & & $\begin{array}{c}++ \\
++\end{array}$ & $\bar{z}$ & $\bar{z}$ & $\begin{array}{l}++ \\
+\end{array}$ & + & \pm & $\bar{z}$ & $\bar{z}$ \\
\hline 7 & - & - & & ++ & - & - & $\dot{t}$ & + & - & - & - \\
\hline 8 & - & - & & $++t$ & - & - & ++ & + & + & - & - \\
\hline 9 & $\bar{z}$ & $\bar{z}$ & ++++ & $\begin{array}{l}+++ \\
++\end{array}$ & $\bar{z}$ & $=$ & ++ & \pm & + & - & - \\
\hline \multirow{2}{*}{\multicolumn{12}{|c|}{ Group 3}} \\
\hline & & & & & & & & & & & \\
\hline 1 & - & - & +++ & ++ & - & - & - & - & - & - & - \\
\hline 2 & - & - & & ++ & - & - & - & - & - & - & - \\
\hline $\begin{array}{l}3 \\
4\end{array}$ & $\overline{-}$ & - & $\begin{array}{c}++++ \\
++\end{array}$ & $\begin{array}{c}+++ \\
++\end{array}$ & $\bar{z}$ & - & - & $=$ & $=$ & $\overline{-}$ & - \\
\hline 5 & - & - & +++ & $+T$ & - & - & - & - & - & - & - \\
\hline 6 & - & - & +++ & ++ & - & - & - & - & - & - & - \\
\hline 7 & - & - & $1+i$ & + & - & - & - & - & - & - & - \\
\hline 8 & - & - & ++++ & +++ & - & - & - & - & - & - & - \\
\hline 19 & $\overline{-}$ & $\overline{-}$ & +++ & ++ & z & $\overline{-}$ & $\overline{-}$ & $=$ & $\bar{z}$ & = & $\overline{-}$ \\
\hline
\end{tabular}

* Group 2 was killed 3 days after the injection; group 3 was killed at 10 days.

it was heavily concentrated in the lamina propria below the crypts but was also present in many of the villi, denser at the center of the villous core. The pattern of iron in the villi was reversed when iron was given by mouth, i.e., denser at the basement membrane with little or none in the core.

\section{DISCUSSION}

Much of the iron-dextran injected into the peritoneal cavity was probably picked up by the lymphatics and delivered to the venous circulation through the thoracic duct. Even red cells transfused into the peritoneal cavity are delivered to the

TABLE II

Distribution of iron in various tissues after intraperitoneal injection of $150 \mathrm{mg}$ of iron as iron-dextran in 3 daily doses of $50 \mathrm{mg}$ *

\begin{tabular}{|c|c|c|c|c|c|c|c|c|c|c|c|}
\hline $\begin{array}{c}\text { Rat } \\
\text { no. }\end{array}$ & Heart & Lung & Liver & Spleen & Kidney & Stomach & $\begin{array}{c}\text { Duo- } \\
\text { denum }\end{array}$ & $\begin{array}{l}\text { Jeju- } \\
\text { num }\end{array}$ & Ileum & Colon & Muscle \\
\hline \multicolumn{12}{|c|}{ Group 4} \\
\hline 1 & - & - & $++t+$ & $++t$ & - & - & ++ & ++ & + & - & - \\
\hline 2 & - & - & & & - & & & & $\frac{1}{1}$ & - & - \\
\hline 3 & - & - & & $+t$ & - & - & ++ & + & + & - & - \\
\hline 4 & - & - & & & - & - & +1 & + & + & - & - \\
\hline 5 & - & - & & & - & - & $+t$ & + & + & - & - \\
\hline 6 & $\overline{-}$ & $\overline{-}$ & & & - & $\bar{z}$ & $++t$ & ++ & $+\dot{t}$ & - & - \\
\hline $\begin{array}{l}7 \\
8\end{array}$ & $\Xi$ & $\bar{z}$ & 十 & + & $\bar{z}$ & $=$ & +1 & + & \pm & $\bar{z}$ & $\bar{z}$ \\
\hline 9 & $\overline{-}$ & $=$ & & & $\overline{-}$ & - & ${ }^{\top} T$ & $T$ & $I$ & - & - \\
\hline 10 & - & - & + & ++ & - & - & $++t$ & $+t$ & + & - & - \\
\hline \multicolumn{12}{|c|}{ Group 5} \\
\hline 1 & - & $+t+$ & $+t+t$ & $++t$ & ++ & - & - & - & - & - & - \\
\hline 2 & - & & & & & - & - & - & - & - & - \\
\hline 3 & - & & & & & - & - & - & - & - & - \\
\hline 4 & - & +- & & $t$ & & - & - & - & - & - & - \\
\hline 5 & - & & & + & & - & - & - & - & - & - \\
\hline 6 & - & & & & & - & - & - & - & - & - \\
\hline 7 & - & & & & & - & - & - & - & - & - \\
\hline 8 & - & $++\dot{t}$ & ++1 & $+t$ & $++t$ & - & - & - & - & - & - \\
\hline $\begin{array}{r}9 \\
10\end{array}$ & $\overline{-}$ & $++t$ & & $t$ & $+\stackrel{+}{+}$ & $\bar{z}$ & $\overline{-}$ & $\bar{z}$ & $\bar{z}$ & $\bar{z}$ & $\bar{z}$ \\
\hline
\end{tabular}

* Group 4 was killed 3 days after the last injection; group 5 was killed at 10 days. 
TABLE III

Distribution of ferritin in rats with a herniated loop of upper jejunum*

\begin{tabular}{|c|c|c|c|c|c|c|}
\hline $\begin{array}{l}\text { Rat } \\
\text { no. }\end{array}$ & $\begin{array}{l}\text { Gut proximal } \\
\text { to the loop }\end{array}$ & $\begin{array}{l}\text { Gut in the } \\
\text { loop }\end{array}$ & $\begin{array}{l}\text { Gut distal } \\
\text { to the loop }\end{array}$ & Liver & Spleen & Omentum \\
\hline \multicolumn{7}{|c|}{ Group 6} \\
\hline $\begin{array}{l}1 \\
2 \\
3 \\
4 \\
5 \\
6\end{array}$ & $\begin{array}{l}++ \\
+ \\
++ \\
+ \\
++ \\
++\end{array}$ & $\begin{array}{l}- \\
- \\
- \\
- \\
-\end{array}$ & $\begin{array}{c}++ \\
+ \\
++ \\
+ \\
+ \\
+\end{array}$ & $\begin{array}{l}++++ \\
++++ \\
++++ \\
++++ \\
++++ \\
++++\end{array}$ & $\begin{array}{l}++++ \\
++++ \\
++++ \\
++++ \\
++++ \\
++++\end{array}$ & $\begin{array}{l}++++ \\
++++ \\
++++ \\
++++ \\
++++ \\
++++\end{array}$ \\
\hline \multicolumn{7}{|c|}{ Group 7} \\
\hline $\begin{array}{l}1 \\
2 \\
3\end{array}$ & $\begin{array}{l}++++ \\
++++ \\
++++\end{array}$ & $\begin{array}{c}++++ \\
+++ \\
+++\end{array}$ & $\begin{array}{c}+++ \\
+++ \\
++++\end{array}$ & $\begin{array}{l}++++ \\
++++ \\
++++\end{array}$ & $\begin{array}{l}++++ \\
++++ \\
++++\end{array}$ & $\begin{array}{l}- \\
-\end{array}$ \\
\hline
\end{tabular}

* The loop was out of the peritoneal cavity and under the skin. Group 6 received an intraperitoneal injection of $50 \mathrm{mg}$ of iron as iron-dextran and was killed 3 days after the injection. Group 7 received $25 \mathrm{mg}$ by mouth and was killed at 3 days. When $4^{+}$: liver $>$spleen $>$omentum.

blood by this route (2). Iron thus cleared from the peritoneum would then be distributed as iron injected intravenously and that which was not required for hemoglobin and other active iron pigments would be placed in storage.

The iron storage protein is called apoferritin when it is free of iron. In the organs where iron is normally stored (liver, spleen) and where it is absorbed and utilized (small intestine, bone marrow) apoferritin is available or can be rapidly synthesized. It may also appear in other organs in conditions of iron overload, as it did in these experiments when it was found in the lungs and kidneys after 10 days but not after 3 . The appearance of ferritin in the small intestine was the reciprocal of this; it was present at 3 days and had disappeared at 10 . This shifting distribution of ferritin iron suggested that the small intestine might have become a depot as a matter of expediency when the storage facilities were suddenly saturated. Iron was placed in available intestinal ferritin until more ferritin could be made available elsewhere, in lung and kidney. This hypothesis was invalidated by injecting the iron intravenously. The ferritin in the gut was not used as a staging depot.

The loop of gut brought out of the peritoneal cavity prior to injection of the iron did not accumulate any ferritin, while the duodenum and jejunum adjacent to the loop had amounts of ferritin which were rated 1 or 2 plus. This indicated that the iron in the small intestine had been re- ceived from the peritoneal cavity by way of the serosa and was held for a time as ferritin prior to movement elsewhere.

It was considered possible that the extraperitoneal loop might have lost its ability to form ferritin, but this possibility was disproved by feeding iron to the animals and demonstrating ferritin in the herniated loops.

The small intestine seems capable of obtaining iron from the peritoneal cavity. This is significant because the serosal surface of the intestine is not known to be an absorptive organ. However, this does not appear to be an absorptive phenomenon in the usual sense. The intraperitoneal iron evidently gains access to the gut through the serosa by diapedesis of iron-laden mononuclear phagocytes and is then deposited within the lamina propria. The function appears to be limited to the small intestine, for no ferritin was found in the colon or in the stomach.

Unless the iron from red cells lost in the peritoneum is recovered in similar fashion, the phenomenon may have little to do with ordinary iron metabolism. Nevertheless, the physiological implications are interesting, because it has been demonstrated that the cleansing of a contaminated peritoneum is accomplished not only by lymphatic drainage but also by diapedesis of laden phagocytes into tissues of the small intestine. It may also be noteworthy that iron which was injected into tissues at the base of the tail later appeared in the terminal ileum (see Results). It is suggested 1) 
that refuse-laden phagocytes from various parts of the body may find their way to the small intestine, and 2) that the small intestine may be an excretory organ for such cells and the debris which they carry. The existence of such a function of the human small intestine is suggested by Astaldi and Strosselli's description of pigment-laden cells which apparently cross the intestinal mucosa and go into the lumen of the gut (3).

\section{SUMMARY}

1. Methods for extraction of ferritin have been modified to permit crystals to be obtained from $500 \mathrm{mg}$ of tissue, or less. A rough estimate of relative ferritin content was possible by counting the crystals in a standard volume.

2. In normal young rats crystalline ferritin was extractable only from the liver.

3. Three days after intraperitoneal injection of iron-dextran, ferritin was found in the small intestine, but at 10 days it was no longer there. When iron was given intravenously it did not accumulate in the small intestine. No ferritin was found in the stomach or colon at any time.

4. A loop of duodenojejunal intestine was brought outside the peritoneal cavity prior to intraperitoneal injection of iron. No ferritin could be recovered from this herniated loop of gut, although it was recovered from the intestine adjacent to the loop. This indicated that the iron came through the serosal surface of the gut.

5. It is concluded that the ferritin which is present in the small intestine after intraperitoneal injection of iron-dextran is derived from iron or iron-dextran which penetrates the serosal surface of the intestine. Histological studies indicate that the iron is carried into the intestinal tissues by diapedesis of iron-laden phagocytes. It is suggested that the small intestine may be an excretory organ for debris-laden phagocytes.

\section{REFERENCES}

1. Granick, S. Ferritin. I. Physical and chemical properties of horse spleen ferritin. J. biol. Chem. 1942, 146, 451.

2. Hedenstedt, S. Elliptocyte transfusions as a method in studies on blood destruction, blood volume, and peritoneal resorption. Acta chir. scand. 1947, 95, suppl. 128.

3. Astaldi, G., and Strosselli, E. Biopsy of the normal intestine. Amer. J. digest. Dis. 1960, 5, 175. 